\title{
Observation of Low Latitude Ionosphere by the Impedance Probe on Board the Hinotori Satellite
}

\author{
Hiroshi Oya, Tadatoshi TaKahashi, and Shigeto Watanabe \\ Geophysical Institute, Tohoku University Sendai, Japan
}

(Received December 12, 1984; Revised November 11, 1985)

\begin{abstract}
By the impedance probe (IMP) on board the Hinotori satellite, that was launched on February 21, 1981, into the semi-equatorial orbit with inclination of $31^{\circ}$ and nearly constant altitude of $650 \mathrm{~km}$, data of electron density profiles along more than 1500 orbits have been obtained with an error less than $\pm 3 \%$. The detected profiles of electron density contain the data of the equatorial plasma bubbles. Preliminary statistic studies on the occurrence frequency indicate that there are at least three types of the plasma bubbles. The plasma bubbles that belong to the first type grow mainly from the evening to the midnight period with large depletion rates of electron density; since the depletion regions are sequencially aligned those are called here multiple plasma bubbles (MPB). The second type plasma bubbles are enhanced mainly after midnight, even in sunlit condition, with periodic features and are called here quasi periodic plasma bubbles (QPB). There is a third type of plasma bubble characterized by its solitary features called here solitary plasma bubble (SPB). The SPB phenomena takes place in all of the night time period. In the topside region of the ionosphere near the edge of the occurrence region of the plasma bubble, there frequently appear electron density enhancements with deviation of a few percent to the background electron density. These newly discovered phenomena are called here plasma blob. Occurrence characteristics of the plasma blob are also discussed.
\end{abstract}

\section{Introduction}

On the satellite HINOTORI (ASTRO-A) that was launched on February 21, 1981 , into an approximately circular orbit with the initial altitude of $650 \mathrm{~km}$ and the inclination of $31.4^{\circ}$, the swept frequency impedance probe (IMP) and the electron temperature probe (TEL) are installed for the monitoring the ionosphere in addition to the main mission for observations of the solar phenomena. For a period more than 15 months after the turning on of the IMP equipment on February 22, 1981, electron density profiles along almost all of the 1500 satellite paths have been accumulated.

In this paper, we describe instrumentation of the IMP system and the results of the initial phase of observations as a general introduction to succeeding reports of IMP studies that will be published in the near future. By analyses of the observed data, many interesting and important aspects of the structure of the ionospheric $F$ region have been disclosed. Especially, accurate measurements of electron density indicate existence of the depletion regions of the electron density that are called the equatorial 
plasma bubbles. In the initial phase of observation, new phenomena in which the electron density profiles show the localized increasing was discovered. The feature of the localized increments of the electron density that is called here "plasma blob" is also described.

The plasma density depletion, that occurs in the equatorial region have been observed with many techniques such as rocket observations (SZUSZCZEWICZ et al., 1980; NARCISI and SZUSZCZEWICZ, 1981; and RINO et al., 1981), radar observations (FARLEY et al., 1970; WOODMAN and LAHOZ, 1976; TSUNODA, 1980a, 1980b, 1980c, 1981; TSUNODA and WHITE, 1981; TSUNODA et al., 1982), satellite observations (CLARK and RAITT, 1976; MCClURE et al., 1977; BURKE et al., 1979; ANDERSON and RUSCH, 1980; and MULDREW, 1980), radio wave scintillation techniques (AARONS et al., 1980), airglow techniques (SOBRAL et al., 1980; WEBER et al., 1980; and SIPLER et al., 1981), and combination of the radar and rocket techniques (SZUSZCZEWICZ et al., 1980; BASU et al., 1980). As results of these observations, it was confirmed that the equatorial plasma bubbles are identical with the radar backscatter plumes that are clarified as being generated in the bottom side of the $F$ layer. Theoretical studies on the equatorial plasma bubble have been carried out (OTT, 1978; OSSAKOW et al., 1979; OSSAKOW and CHATURVEDI, 1978; ZALESAK and OSSAKOW, 1980; FEJER and KELLY, 1980; OSSAKOW, 1981; and ZALESAK et al., 1982) considering the Rayleigh Taylor instability both in the linear and nonlinear regimes. Though the developments of the equatorial plasma bubble have thus been understood, detailed studies for confirmation of the proposed theories has not been made yet. For this purpose, investigations on the occurrence characteristics of the plasma bubbles depending on local times and seasons, and the spatial parameters such as magnetic dip latitudes, and longitudes are needed. Studies on the fine structures and the time dependent variation of the plasma bubbles and blobs are also very important clues to study on the dynamical behaviour, such as the growth, the decay and movements of the plasma bubbles. The data observed by Hinotori satellite are expected to provide important data for these subjects.

\section{IMP System and Operations}

The swept frequency impedance probe was developed for measurements of the ionospheric electron density from the upper hybrid resonance of the antenna impedance immersed in plasma (OYA and OBAYASHI, 1966; OYA, 1968). The swept frequency impedance probe was originally developed for sounding rocket observations by measuring both the amplitude and the phase values of the impedance versus the swept frequency in a range where the sheath resonance and the upper hybrid resonance frequencies are included. In the sounding rocket experiment, all the measured amplitude and phase data are transmitted to the ground in a form of analog data through FM-FM telemetry systems. Since we are allowed for using relatively low bit rate PCM telemetry channels, an onboard data handling system was employed to reduce data rate for sending to the ground, i.e., an automatic detection of the resonance frequencies, such as the upper hybrid resonance and the sheath resonance 
frequencies was made. Automatic detection of the upper hybrid resonance frequency was first carried out in the gyro-plasma probe installed on the Denpa (REXS) satellite for the measurement of the ionospheric electron density in an altitude up to $6300 \mathrm{~km}$ (EJIRI et al., 1973). The same system is further used in IMP instrument on board the Taiyo satellite (OYA and MORIOKA, 1975) by adding noise elimination circuits. In the IMP system on board the Hinotori satellite the same principle with the previously developed gyro-plasma probe on board the satellite was applied.

A block diagram of IMP system installed on the Hinotori satellite is shown in Fig. 1. A sinusoidal signal swept from $200 \mathrm{kHz}$ to $10.2 \mathrm{MHz}$ generated in a swept frequency generator is fed to the cylindrical probe of $40 \mathrm{~cm}$ length and $1 \mathrm{~cm}$ diameter, that is set at the top edge of a solar paddle. The RF component of electrical potential of the probe immersed in the plasma is detected through a bridge circuit. This potential is strictly related to the impedance value since the potential is measured as a reaction of impressed current from the signal generator to the probe. The resonance detector of the IMP system, automatically detects the minimum and samples the signal level corresponding to the impedance at the upper hybrid resonance frequency $f_{\text {UHR }}$. The amplitude of probe impedance is also sampled at frequencies of $200 \mathrm{kHz}$, and $400 \mathrm{kHz}$. Along more than 1500 paths after the launching of the Hinotori satellite, the data have been obtained with time resolution of $1 \mathrm{sec}$. The IMP observation is limited to periods of the quiet solar activity called the quiet mode operation, since the data transmission becomes busy for the observations in the case of the solar flare.

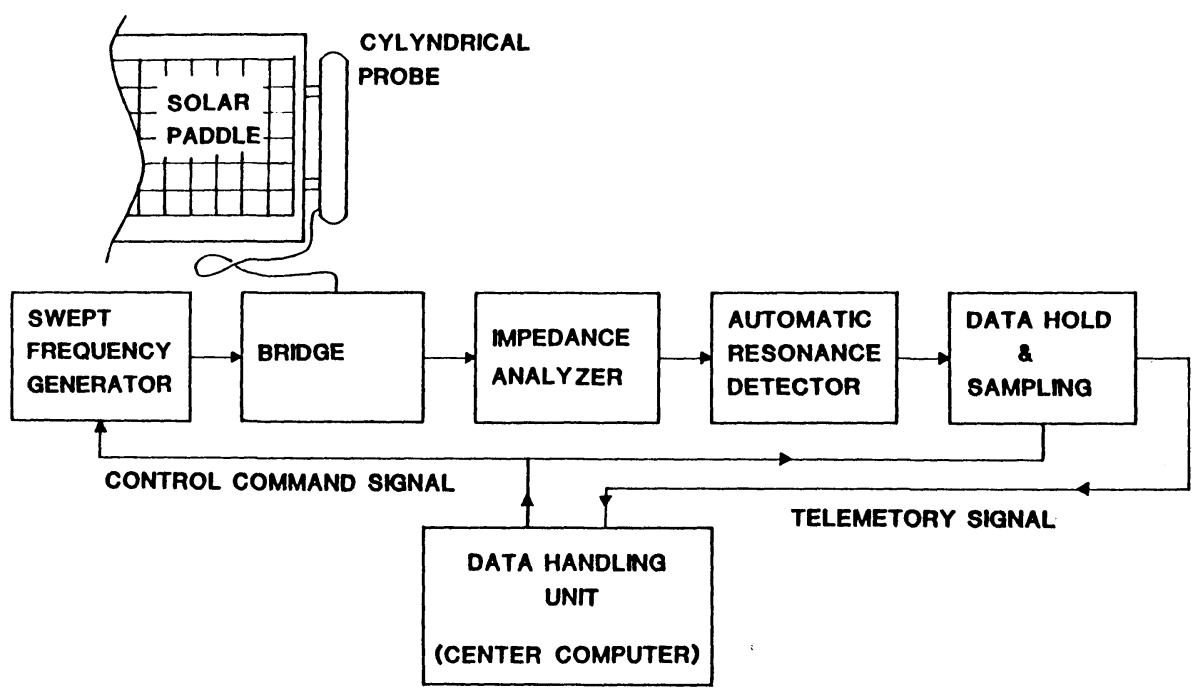

Fig. 1. Block diagram of the impedance probe. Swept frequency generator that is controlled by the control command signal feeds the sinusoidal signal, through the bridge circuit, to the cylindrical probe, that is set at the tip of the solar paddle. Signal from the probe is measured by the impedance analyser. After automatic detection of the resonance points, holded data from the automatic detection circuit of the resonance point are sampled to send the telemetry system. 


\section{Electron Density Profiles}

\subsection{Typical data}

In Fig. 2, example data of the electron density distribution are shown for sequencially selected three satellite orbits. In this figure the top panel shows the geometrical relation of the each orbit with information of the kind of operations such as the calibration, the real time, and the data recording mode operations. The data displayed from the data recorder are indicated in the middle and the bottom panels. From these data we can investigate the latitudinal and longitudinal dependencies of the electron density distribution in the ionosphere along the satellite path at the height level of $650 \mathrm{~km}$. The periodically appearing depletion profiles of the electron density is due to the wake effects produced by the moving satellite. Except for this wake effect all of the variations shown in the data are real ionospheric structure. These features show the electron density profiles of i) equatorial anomalies with a fairly good symmetry around the magnetic equator; black dots in the top panel indicate positions of the double humped peaks of the equatorial anomaly as has been indicated in the middle and the bottom panels, and show the electron density profiles of ii) wavy repetition pattern in the night time period (see arrows in the middle and the bottom panels); the result is consistent with that obtained from the analyses of the Taiyo satellite data (OYA et al., 1982).

\subsection{Plasma bubbles and blobs}

One of the most remarkable features in the results of the IMP observations is irregularities of electron density distribution in the equatorial ionosphere. During the initial 15 months of the Hinotori satellite observations, more than 1000 cases of the irregular structures have been observed. Most of these irregular structures show depletions of electron density from the background ionospheric plasma density, that is called the equatorial plasma bubbles, while there is a few cases of the increase of the plasma density which is newly discovered by this Hinotori satellite observation. This new finding is here called plasma blob. Typical examples of the plasma blob are given in Fig. 3. Details of the plasma blob will be discussed in different papers in the near future.

One of the frequently observed feature of the plasma bubble is characterized by formation of a group of plasma bubbles in which each plasma bubble is distributed with random distances. This type of the plasma bubble is, here, called "Multiple Plasma Bubble (MPB)". In Fig. 4, a typical example of MPB from the observation data made on September 18, 1981 is given. The data are modulated with the spin period of the satellite due to periodic sweeping of the probe through the wake region. Independently to the wake effect, there are remarkable groups of depletion regions (plasma bubbles) of the electron density profile (see the portions indicated by arrows in Fig. 4), it is disclosed, for the first time by this work, that the maximum depletion rate is almost $10^{-3}$ to the background density. This type of equatorial plasma bubbles is identical with the previously reported equatorial plasma plumes detected by the incoherent backscatter radar observation from the ground (for examples, WoODMAN 


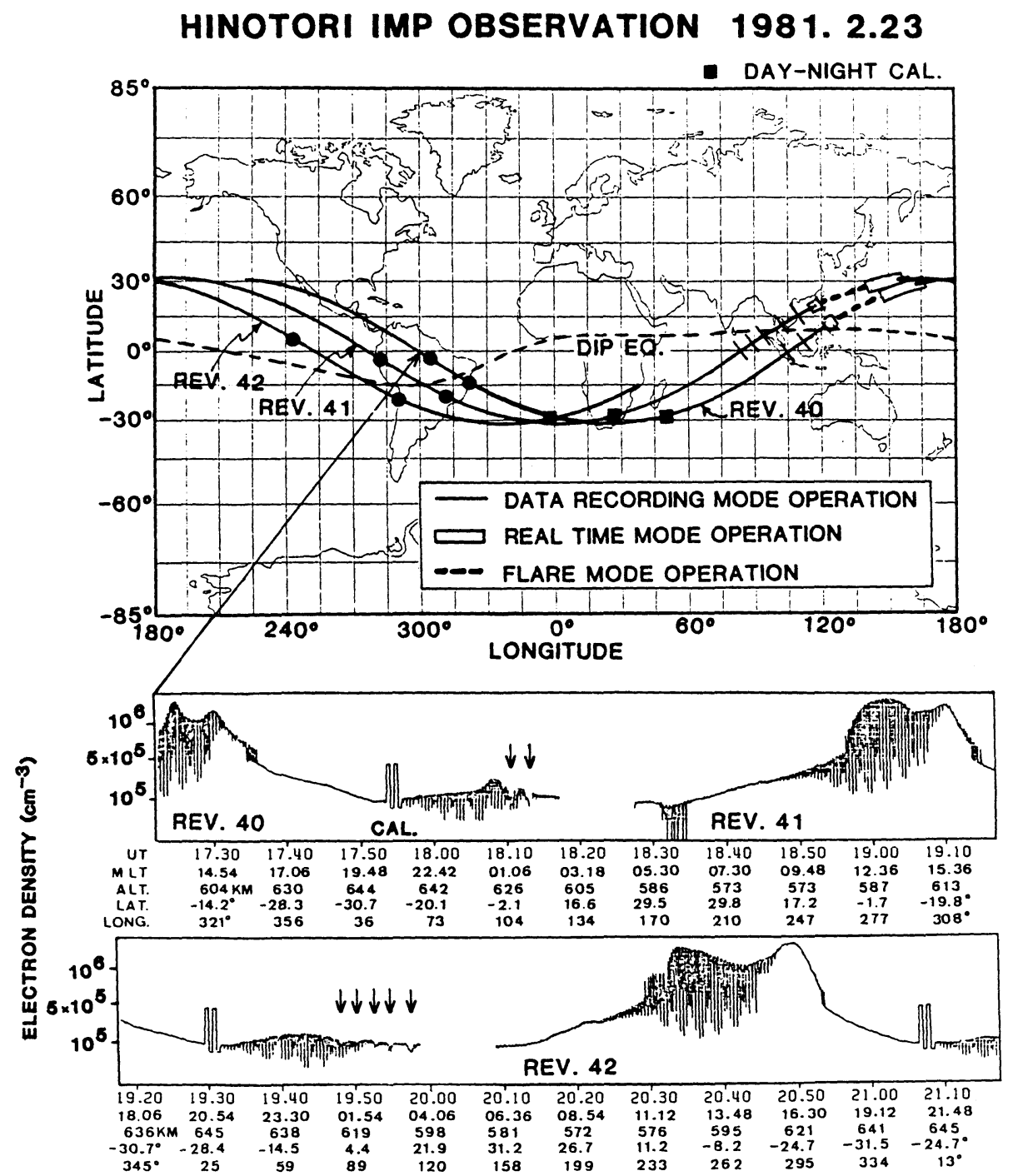

Fig. 2. Example records of the Hinotori satellite. The top panel shows sequencially selected three orbits where the periods of data recording mode operation (solid curves) real time mode operations (long squares) and flare mode operation (dotted lines) are indicated. The black dotts indicate the region of peak values of electron density in the equatorial anomaly. Middle and the bottom panels show the example electron density profiles along the orbits Rev 40 and $\operatorname{Rev} 42$, respectively, where the plasma bubbles are indicated with arrows.

and LAHOZ, 1976; TSUNODA, 1980a, 1980b, 1980c), that appear in the equatorial ionosphere in the period of post sunset. In Fig. 5, a typical example of the periodically distributed plasma bubbles is indicated for the succeeding three orbits of observa- 


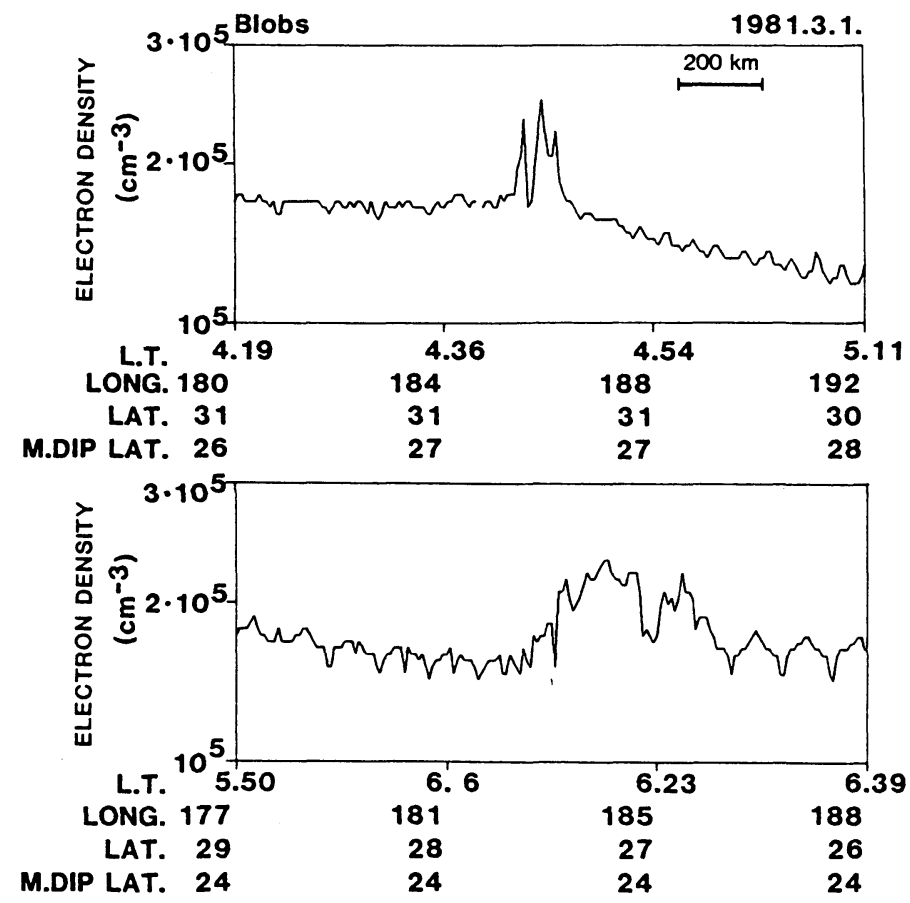

Fig. 3. Example record of newly discovered plasma blob. Remarkable increases of electron density from the average back ground density with factor of 2 are indicated both in the top and bottom panels observed on May 1 in 1981 from 4:19-5:11 LT and 5:50-6:39 LT, respectively. The periodic variation of the electron density is caused by periodic sweeping of the probe through the wake regions due to the satellite spin.

tions. From the time evolution of the plasma bubbles during the three succeeding satellite orbits, formation and decay processes of this type of plasma bubble are suggested. The group of bubbles is here called "Quasi Periodic Plasma Bubble (QPB)". In this case, a wave like distribution of electron density is observed around 7:55 UT with minima at the positions given by labels a, b, c, and A in the observation data obtained on the path of Rev. 481 (corresponding positions given in the bottom panel for $\mathrm{c}$ and $\mathrm{A}$ ). These wavy patterns are considered to be a manifestation of the TID disturbance caused by the auroral substorm (OYA et al., 1982). In the succeeding orbit of Rev. 482, a pair of large depletion regions of the plasma density are formed. These developed plasma bubbles are apparently produced being associated with the steeply developed gradient of the background plasma density in the horizontal direction. After the formation of the plasma bubbles, the positions of plasma bubbles make slight movement across the magnetic field line. This movement can be attributed to the drift motion due to the ionospheric electric field. The depletion region is most likely developed along the magnetic field line as has been pointed out by DYSON and BENSON (1978). 


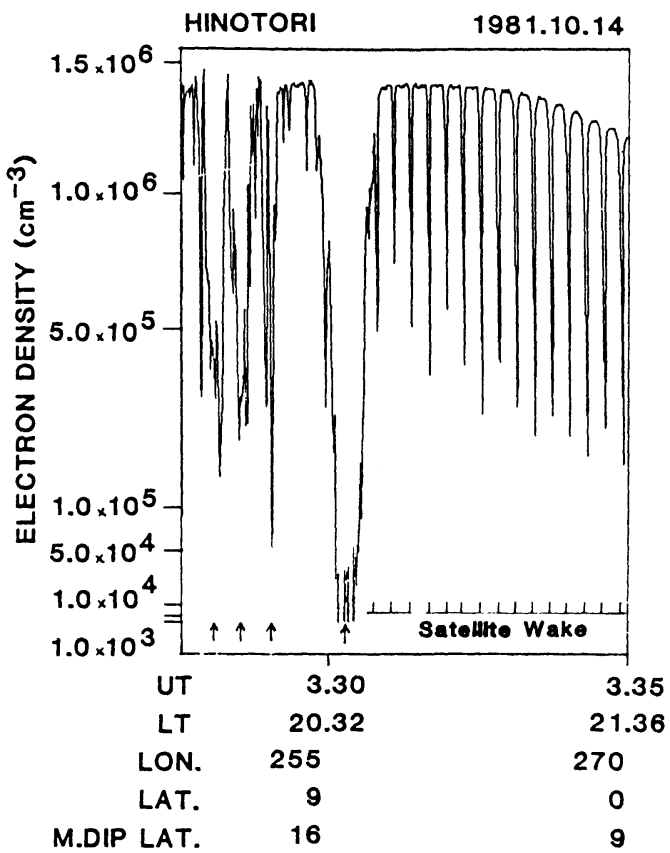

Fig. 4. Example of the multiple plasma bubble (MPB) observed on September 18, 1981. Very large depletions of the electron density are indicated (see the portions indicated by the arrows). The periodic variation of the electron density is caused by the periodic sweeping of the probe through the wake region due to the satellite spin.

In contrast with the above mentioned two types of the plasma bubbles, there are solitary type irregularities of plasma density distribution called here "Solitary Plasma Bubble (SPB)". An example of the solitary plasma bubble is given in Fig. 6 in which the solitary plasma bubble is indicated as a region of density depletion.

4. Occurrence of the Plasma Bubbles and Blobs

The occurrence characteristics of all these plasma bubble phenomena have been analysed for the dependency on the local time, and the magnetic dip latitude. In Fig. 7 , the dependency of plasma bubble occurrence on the local time is indicated in term of the occurrence probability. The occurrence probability of the plasma bubble is defined as ratio of the occurrence frequency of the plasma bubble to the frequency of the observation chance at a given region of the ionosphere. Almost all of the phenomena take place during the night time period from 18 LT to $6 \mathrm{LT}$ always through midnight with a few exceptions for data observed in the morning time between $6 \mathrm{LT}$ and $10 \mathrm{LT}$.

The occurrence probability shows two major peaks at around $22 \mathrm{LT}$ and around 

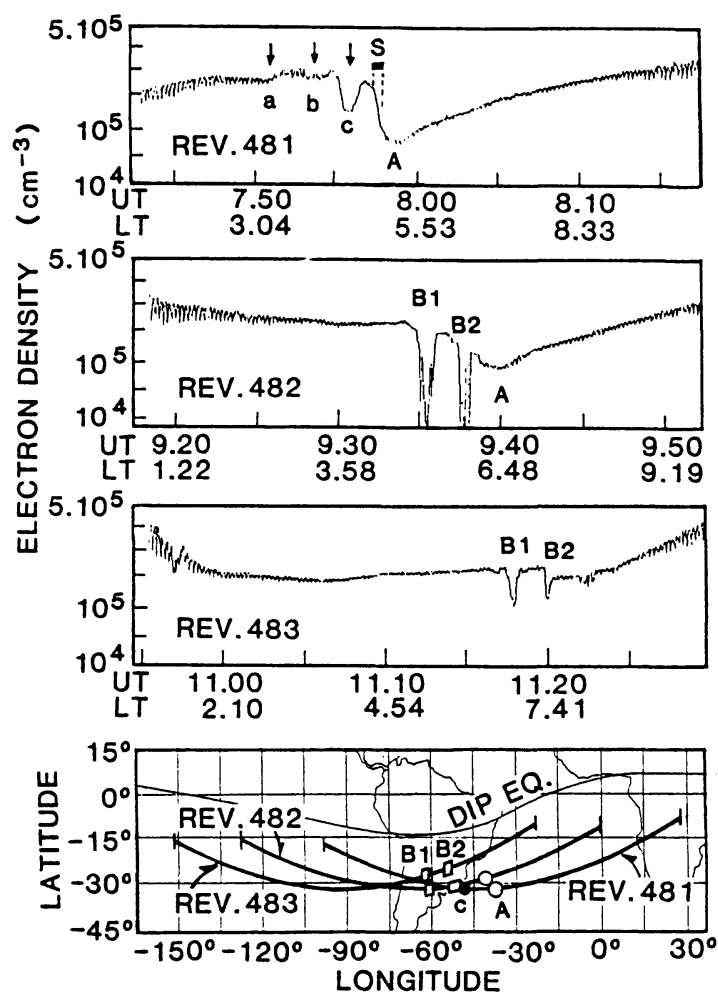

Fig. 5. Time variation of the plasma bubbles detected in the three succeeding orbits, Rev. 481, 482 and 483. Corresponding to oscillating back ground electron density (see top panel), the formation of the plasma bubble takes place especially in the region of the steep gradient of the back ground electron density (especially written by s). The bubbles grow as indicated by $B_{1}$ and $B_{2}$ in the second panel. After 90 minutes from the maximum development of the plasma bubble, the formed plasma bubbles start to fading out as have been indicated in the third panel. Corresponding positions of the observed plasma bubbles are indicated in the bottom panel.

$3 \mathrm{LT}$. In addition to these two peaks there are another two sub-peaks in the occurrence of the plasma bubbles; the first is in the evening period around $20 \mathrm{LT}$ (see 1, in Fig. 7) and the second is in the morning period around $7 \mathrm{LT}$ (see 4, in Fig. 7). The major peak at $22 \mathrm{LT}$ (see 2, in Fig. 7) and the sub-peak at $20 \mathrm{LT}$ are associated with the occurrence of the multiple plasma bubbles, while the second peak of the plasma bubble occurrence around 3 LT (see 3, in Fig. 7) is mainly associated with the quasi periodic plasma bubbles. The occurrence probability of the solitary plasma bubble shows a maximum in the midnight period. Seasonal dependency of the occurrence of the plasma bubble is also indicated in the results given in Fig. 8; that is, the occurrence probability of the plasma bubble in the equinox periods is clearly large than the occurrence probability in the summer and winter seasons. 


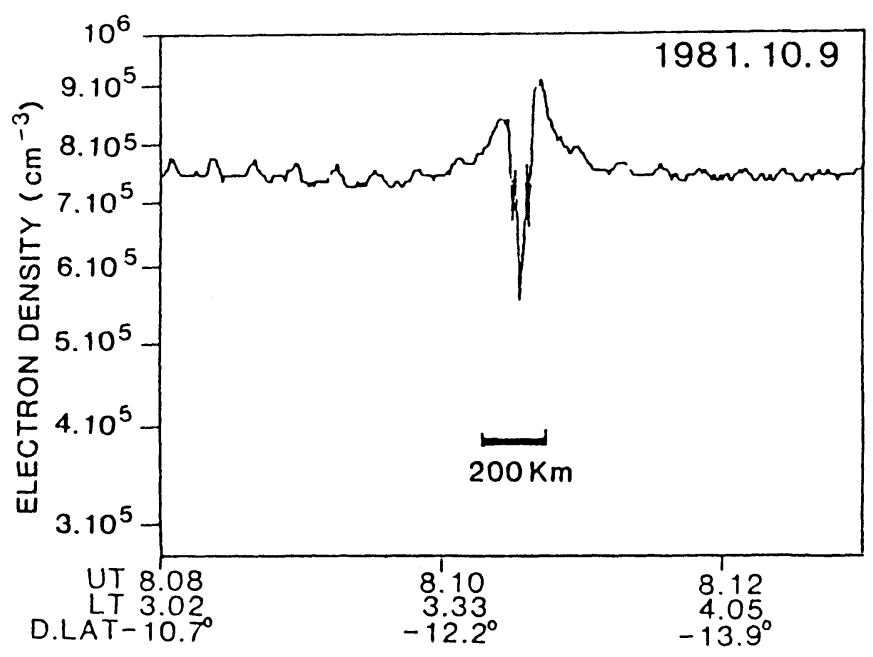

Fig. 6. Typical example of the solitary plasma bubble. In the midst of a region, where plasma density is increasing gradually with characteristic length of $200 \mathrm{~km}$, a region of steep plasma density depletion is indicated.

In Fig. 8, spatial distribution of the plasma bubbles is indicated. The occurrence of the plasma bubble around the equator is quite evident; and the occurrence is localized in the range within $\pm 20^{\circ}$ in geomagnetic dip latitude centered around the magnetic equator. The localization of the occurrence of the plasma bubble near the magnetic equator suggests that the relationship of the magnetic field vector with respect to the earth's gravity field may be key factors for generation of the plasma bubble; the magnetic field vector is almost perpendicular to the gravity field vector in this region. The possible effects of the crossfield instabilities in addition to the Rayleigh-Taylor instability may also be important because the equator region satisfies the condition of the cross-field instabilities (FARLEY, 1963; TSUDA et al., 1966; SATO, 1973).

Occurrence of the plasma blob is characterized by its complementary nature of the irregularities with respect to the plasma bubble. That is, the occurrence of the plasma blob takes place in the topside region of the ionosphere while the plasma bubbles are formed originally in the bottom side of the ionosphere. The complementary feature is also evident in the occurrence region, the plasma blob is only observable in two sub-tropical regions with the magnetic latitudes between $20^{\circ}$ and $25^{\circ}$ in the northern hemisphere and $-20^{\circ}$ and $-25^{\circ}$ in the southern hemisphere. These regions are corresponding to the edge of the occurrence region of the plasma bubbles. Though there are many interesting evidences for the plasma blob phenomena, the detail of the occurrence characteristics defer to the other paper (WATANABE and OYA, 1986). 


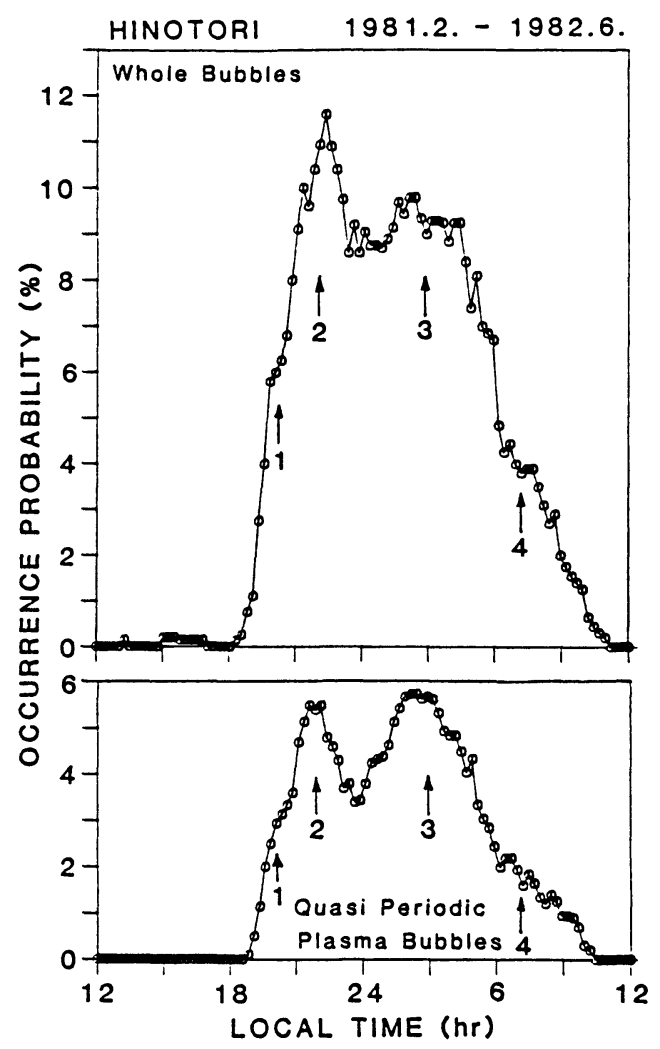

Fig. 7. Occurrence probability of the plasma bubbles versus the local time. Top panel shows the whole occurrence of the plasma bubble whithin the total latitudinal range preferable to the occurrence of the plasma bubbles and also being integrated over the longitude; and bottom panel shows the occurrence probability of the quasi periodic plasma bubbles versus the local time, again the occurrences are integrated over whole geomagnetic latitude and longitude. Arrows at 1,2,3 and 4 indicate the existing local maxima (sometimes hidden maxima which are only shown as break points of curves) at evening, pre-midnight, post-midnight and early morning, respectively.

\section{Summary}

The swept frequency impedance probe on board Hinotori satellite has been developed as a result of a long history of the observations using the ionospheric sounding rocket and also the observations by the Denpa and Taiyo satellites. The data currently provides the survey data of electron density at an altitude of $650 \mathrm{~km}$ with accuracy within an error of $\pm 3 \%$. Preliminary analyses using these data indicate important characteristics of the equatorial plasma bubbles.

The newly discovered features of the equatorial plasma bubble are classified into three types. The first is the type for multiple plasma bubbles. These multiple plasma bubbles are formed in the evening ionosphere persisting to the midnight, and appear 


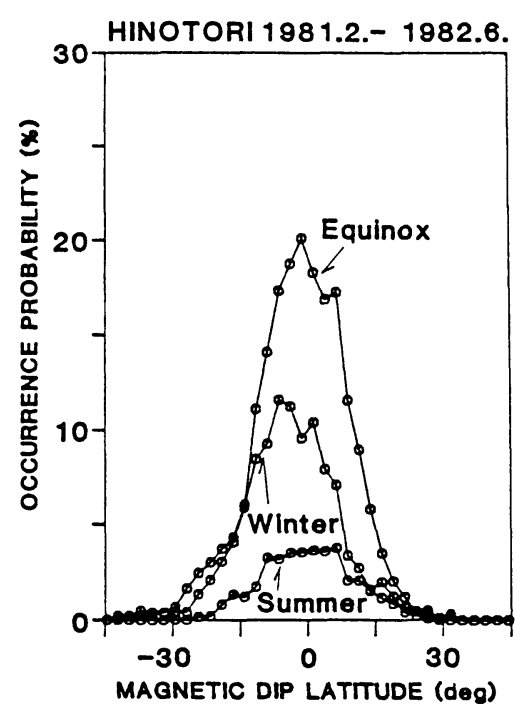

Fig. 8. Seasonal dependence of the spatial distribution of the plasma bubbles. Though the occurrence probability largely depends on the season, the bubbles occur always in the region of the magnetic equator within the magnetic dip latitude range from $-20^{\circ}$ to $20^{\circ}$.

more frequently in the equinox than in the solstices. The second is the type for the quasi periodic plasma bubbles which show array of the plasma bubble with the characteristic distance of several hundred $\mathrm{km}$ to more than $1000 \mathrm{~km}$. This type of the plasma bubble appears even in the morning time under sunlit conditions. The third is for the plasma bubbles called solitary plasma bubble. The occurrence of this solitary plasma bubble is not restricted to a special period, though there is a slight tendency to show maximum occurrence in the midnight.

The plasma blobs that are characterized by the local enhancement of electron density are newly discovered by this work. In the topside region of the ionosphere, the plasma blobs are located near the edge portion of the occurrence region of equatorial plasma bubbles.

Detailed studies using IMP data on the Hinotori satellite are currently continued for investigation of the origin of the plasma bubbles and blobs. The following subjects are also extensively studied based on the data obtained by the swept frequency impedance probe on board the Hinotori satellite:

(a) Statistical studies on characteristics of the occurrence of the equatorial plasma bubbles and its distribution in time and space.

(b) Studies on the morphology of the plasma bubbles with respect to the scale size, the distance between the plasma bubbles, the depletion depth of electron density, the gradient of plasma density in the boundary region of the bubble and their distribution.

(c) Studies on interrelations of the post-midnight ESF (Equatorial Spread $F$ ) 
events and the other ionospheric phenomena such as TID.

(d) Dynamical aspects of plasma bubbles such as drift motion, growth and decay rates using sequential observation data showing the time history of the existing plasma bubbles.

The detailed reports on these studies are deferred to future works.

The mission of the Hinotori satellite had been carried out in the Institute for Space and Astronautical Science, Ministry of the Education, Japan being managed by Profs. M. Oda and Y. Tanaka, the authors would like to express their sincere thanks to all of the member committed to the Hinotori satellite mission for successful launching and operation and supports for the data acquisition.

\section{REFERENCES}

Aarons, J., J. P. Mullen, H. E. Whitney, and E. M. Mackenzie, The dynamics of equatorial irregularity patch formation, motion, and decay, J. Geophys. Res., 85, 139-149, 1980.

Anderson, D. N. and D. W. Rusch, Composition of the nighttime ionospheric $F_{1}$ region near the magnetic equator, J. Geophys. Res., 85, 569-574, 1980.

Basu, S., J. P. McClure, S. Basu, W. B. Hanson, and J. Aarons, Coordinated study of equatorial scintillation and in situ and radar observations of nighttime $F$ region irregularities, J. Geophys. Res., 85, 5119-5130, 1980.

Burke, W. J., D. E. Donatelli, R. C. Sagalyn, and M. C. Kelly, Low density regions observed at high altitudes and their connection with equatorial spread $F$, Planet. Space Sci., 27, 593-601, 1979.

Clark, D. H. and W. J. RaitT, The global morphology of irregularities in the topside ionosphere, as measured by the total ion current probe on ESRO-4, Planet. Space Sci., 24, 873-881, 1976.

Dyson, P. L. and R. F. BENSON, Topside sounder observations of equatorial bubbles, Geophys. Res. Lett., 5, 795-798, 1978.

EJiri, M., H. Oya, T. Aso, C. Morita, T. Obayashi, S. Urimoto, and H. Yamaki, The gyro-plasma probe on-board the REXS-DENPA satellite, Inst. Space and Aeronautical Sci., Univ. of Tokyo, Report No. 495, 1973.

FARLEY, D. T., A plasma instability resulting in field-aligned irregularities in the ionosphere, J. Geophys. Res., 68, 6083-6097, 1963.

Farley, D. T., B. B. Balsley, R. F. WoOdman, and J. P. MCCluRe, Equatorial spread F: Implications of VHF radar observations, J. Geophys. Res., 75, 7199- 7216, 1970.

FeJER, B. G. and M. C. Kelley, Ionospheric Irregularities, Rev. Geophys. Space Phys., 18, 401-454, 1980.

McClure J. P., W. B. Hanson, and J. H. Hoffman, Plasma bubbles and irregularities in the equatorial ionosphere, J. Geophys. Res., 82, 2650-2656, 1977.

MuldREW, D. B., Characteristics of ionospheric bubbles determined from aspect sensitive scatter spread $F$ observed with Allouette 1, J. Geophys. Res., 85, 2115-2123, 1980.

NARCISI, R. S. and E. P. Szuszczewicz, Direct measurements of electron density, temperature and ion composition in an equatorial spread-F ionosphere, J. Atmos. Terr. Phys., 43, 463-471, 1981.

Ossakow, S. L., Spread-F theories-a review, J. Atmos. Terr. Phys., 43, 437-452, 1981.

Ossakow, S. L. and P. K. Chaturvedi, Morphological studies of rising equatorial spread $F$ bubbles, $J$. Geophys. Res., 83, 2085-2090, 1978.

Ossakow, S. L., S. T. ZalesaK, B. E. McDonald, and P. K. Chaturvedi, Nonlinear equatorial spread $F$ : Dependence on altitude of the $F$ peak and bottomside background electron density gradient scale length, J. Geophys. Res., 84, 17-29, 1979.

OTт, E., Theory of Rayleigh-Taylor bubbles in the equatorial ionosphere, J. Geophys. Res., 83, 2066$2070,1978$.

OYA, H. and T. OBAYASHI, Measurement of ionospheric electron density by a gyro-plasma probe: A rocket 
experiment by a new impedance probe, Rep. Ionos. Space Res. Japan, 20, 199-213, 1966.

OYA, H., Theoretical prediction on discrimination of modified and hybrid plasma resonances, Rep. Ionos. Space Res. Japan, 22, 119-122, 1968.

OYA, H. and A. MORIOKA, Instrumentation and observations of gyro-plasma probe installed on TAIYO for measurement of ionospheric plasma parameters and low energetic particle effects, J. Geomag. Geoelectr., 27, 331-361, 1975.

Oya, H., T. TAKahashi, A. Morioka, and H. MiYaoka, Wavy patterns of ionospheric electron density profiles triggered by TID-Observation results of the electron density by TAIYO satellite, J. Geomag. Geoelectr., 34, 509-527, 1982.

Rino, C. L., R. T. Tsunoda, J. Petriceks, R. C. Livingston, M. C. Kelley, and K. D. Baker, Simultaneous rocket-borne beacon and in situ measurements of equatorial spread $F$-Intermediate wavelength results, J. Geophys. Res., 86, 2411-2420, 1981.

Sato, T., Unified theory of type 1 and 2 irregularities in the equatorial electrojet, J. Geophys. Res., 78, $2232-2243,1973$.

Sipler, D. P., M. A. BIONDi, and R. D. HAKE, Jr., Studies of the motion of equatorial $630.0 \mathrm{~nm}$ airglow depletions, Planet. Space Sci., 29, 1267-1272, 1981.

Sobral, J. H. A., M. A. Abdu, C. J. Zamlutti, and I. S. Batista, Association between plasma bubble irregularities and airglow disturbances over Brazilian low latitudes, Geophys. Res. Lett., 7, 980-982, 1980.

Szuszczewicz, E. P., R. T. Tsunoda, R. Narcisi, and J. C. Holmes, Coincident radar and rocket observations of equatorial spread-F, Geophys. Res. Lett., 7, 537-540, 1980.

Tsuda, T., T. SATO, and K. MAEDA, Formation of sporadic $E$ layers at temperature latitudes due to vertical gradients of charge density, Radio Sci., 1, 212-225, 1966.

TsunODA, R. T., Magnetic-field-aligned characteristics of plasma bubbles in the nighttime equatorial ionosphere, J. Atmos. Terr. Phys., 42, 743-752, 1980a.

TSUNODA, R. T., On the spatial relationship of 1-m equatorial spread $F$ irregularities and plasma bubbles, J. Geophys. Res., 85, 185-190, 1980b.

Tsunoda, R. T., Backscatter measurements of $11-\mathrm{cm}$ equatorial spread $F$ irregularities, Geophys. Res. Lett., 7, 848-850, 1980c.

Tsunoda, R. T., Time evolution and dynamics of equatorial backscatter plumes 1. Growth phase, $J$. Geophys. Res., 86, 139-149, 1981.

TSUNODA, R. T. and B. R. White, On the generation and growth of equatorial backscatter plumes 1 . Wave structure in the bottomside $F$ layer, J. Geophys. Res., 86, 3610- 3616, 1981.

Tsunoda, R. T., R. C. Livingston, J. P. McClure, and W. B. Hanson, Equatorial plasma bubbles: Vertically elongated wedges from the bottomside $F$ layer, J. Geophys. Res., 87, 9171-9180, 1982.

WatANABE, S. and H. OYA, Occurrence characteristics of low latitude ionosphere irregularities observed by impedance probe on board the Hinotori satellite, J. Geomag. Geoelectr., this issue, 125-149, 1986.

Weber, E. J., J. Buchau, and J. G. Moore, Airborne studies of equatorial $F$ layer ionospheric irregularities, J. Geophys. Res., 85, 4631-4641, 1980.

Woodman, R. F. and C. LAHoz, Radar observations of $F$ region equatorial irregularities, J. Geophys. Res., 81, 5447-5466, 1976.

ZALESAK, S. T. and S. L. OsSAKOW, Nonlinear equatorial spread $F$ : Spatially large bubbles resulting from large horizontal scale initial perturbations, J. Geophys. Res., 85, 2131-2142, 1980.

Zalesak, S. T., S. L. Ossakow, and P. K. Chaturvedi, Nonlinear equatorial spread $F$ : The effect of neutral winds and background pedersen conductivity, J. Geophys. Res., 87, 151-166, 1982. 